\title{
Comentario a la Tercera "Meditación Cartesiana" de Husserl
}

Se nos ofrece en esta tercera meditación un concepto "más estricto de constitución" trascendental, una diferenciación estructural de esa extensión amplísima. ¿Qué criterio para hacerla? Husserl lo señala: La existencia y la no existencia, que "bajo el amplio título de razón y sin razón" como correlativos, constituyen un "tema universal de la fenomenología".

Recordemos que la "epojé" no suprime nada, sino suspende, inhibe, detiene juicios sobre la realidad sin modificar, y antes bien, impidiendo lo que sí sería - con tales juicios- modificación de los fenómenos, que quedan, así, puros para el señor Husserl.

La fenomenología tiene pues, como las antiguas casas romanas, su "cave canem": "cuidado con la realidad": "La realidad es puesta por el yo y no pertenece al percibir' $(15,1)$; C'el prejuicio de la existencia del mundo se desliza sin ser notado a través de toda actitud natural" $(15,3)$. Y además la afirmación de que en la experiencia natural está ya la trascendental, sólo que no somos conscientes de ella. Como el can romano, la realidad puede pues, morder, lesionando así la integridad trascendental de la experiencia. Y como un conocido santo del que nos informa una hagiografía, que había recibido de su superior monástico la orden de no hacer más milagros por traer con ellos escandalizado al vecindario, y que pasando por una calle vió a un infeliz albañil que caía de un alto andamio al que tuvo que gritar "espérate que voy a pedir permiso" dejándolo, así, en el aire, hasta que el permiso le fué concedido, así Husscrl deja la existencia, mientras obtiene el permiso de su "superior conventual" la apodicticidad -evidencia perfecta de una perfección mayor aún que la adecuación. Mas hélo aquí con el permiso, haciéndonos el obligatorio milagro de la salvación del "albañil" existencia:

"Entre las variedades de modos de conciencia sintéticamente coherentes que hay para todo objeto presunto, de cualquier categoría y que 
se trata de estudiar en sus tipos fenomenológicos, figuran también aquellas síntesis que tienen, respecto a la correspondiente asunción inicial el típico estilo de modos verificativos, $y$, en especial, de evidentemente verificativos, o por el contrario, el de anulativos y evidentemente anulativos. Correlativamente el objeto presunto tiene el carácter evidente de existente o no existente". "No a los objetos sencillamente, sino al sentido objetivo, se refieren los predicados de existencia e inexistencia y sus modalidades". Que no se dan como datos fenomenológicos y sin embargo tienen origen fenomenológico. De los procesos de verificación dice: "son intencionalidades de grado superior inherentes en disyunción exclusiva a todos los sentidos objetivos".

No reconocemos a nuestro buen amigo el "albañil" existencia. Tiene una palidez cerúlea, está como muerto, de veras no es el que conocimos y conocemos. Tiene ese color descolorido de la existencia "salvada" por cualquier idealismo.

Dice de las intencionalidades de grado superior: son actos y corre latos de la razón que han de brotar esencialmente del ego trascendental. Razón, título no para posibles hechos accidentales- no es facultad fáctico-accidental - sino para una estructura esencial y universal de la subjetividad trascendental. Que nos remite a posibilidades de verificación $y$ éstas al hacer evidente $y$ tener como evidente.

Uno de los conceptos que es indispensable aclarar en la edición castellana de "Las Meditaciones" es el de evidencia. Se olvida la distinción hecha en la traducción de las "Investigaciones" (Revista de Occidente) entre evidencia en generah etEvidenz E's evidencia y evidencia apodíctica -insicht- "intelección". Y es así que en la edición que comentamos el término está usado sin hacer esa distinción, muchas veces con significaciones distintas; esto, si no un defecto de la traducción, es imperdonable falla en quien como el pensador de Moravia habla de la importancia y necesidad de "soldar la significación a la expresión". Si él sabe evitar, pese a ello, los "idola fori" los provoca en cambio en el estudioso.

Dice Husserl: "Un acto de juzgar meramente presuntivo al pasar en la conciencia a la correspondiente evidencia, se ajusta a lasicosas, a los hechos mismos". La evidencia es pues. "un eminente asumir juzgando". "En lugar de estar presente la cosa en el modo del mero asumir a distancia, en la evidencia está presente la cosa ella misma". Es pues, síntesis de identificación concorde( 4 ,4). "La evidencia en el sentido más amplio posible es experiencia de la existencia y esencia de las cosas, un llegar a ver con el espíritu las cosas mismas; la pugna con lo que ella. 
con lo que la experiencia muestra, tiene por resultado el polo negátivo de la evidencia o la evidencia negativa" - cuyo contenido es la falsedad evidente $(5,2)$. "La experiencia en el sentido corriente es una evidencia particular, evidencia en general podemos decir es experiencia en un sentido amplísimo y sin embargo esencialmente unitario". Vale decir que con una mutua ampliación de las acepciones corrientes los términos de evidencia y experiencia pueden considerarse sinónimos en fenomeno.ogía. Es así que Husserl puede hablar, frase sorprendente a primera vista, de "evidencias presuntivas" (28). Al referirse a evidencia en este sentido amplísimo, en el de experiencia, está bastante lejos de la acəpción corriente de evidencia: "Verdad manifiesta".

Caracteriza también a la evidencia como: "protofenómeno universal de la vida intencional". "Preeminente modo de conciencia de la aparición auténtica, del representarse a sí misma, del darse a sí misma una cosa, un hecho objetivo, universal, un valor en el modo terminal del "aquí está", dado directa, intuitiva, originalmente". "Estar con la cosa misma, ver, contemplar, penetrarse de la cosa misma".

Se preguntará: ¿Qué queda en la "clara et distincta preceptio" del insigne antecesor de Husserl? - Si Husserl, en una primera, latísima acepción, identifica evidencia y experiencia, después, cuando habla del alcance de la evidencia, del "hasta dónde" de su perfección, del efectivo darse las cosas mismas (5) y cuando caracteriza la imperfección como "falta de integridad, unilateralidad, relativa oscuridad e indistinción en la auténtica presencia de las cosas o hechos objetivos", cuando describe la evidencia adecuada _o perfecta en el sentido de la adecuación-que es la que permite (proclamar uná validez definitiva $(5,4)$, nos está hablando de la evidencia cartesiana ya que sin "integridad" y con "unilateralidad" no. cabrían, tampoco, claridad y distinción. Aclarar - dice Husserl- es un modo de hacer evidente, y quiere decir evidente de evidencia adecuada. Recordemos que para Descartes "claro es el conocimiento que se hace presente y manifiesto a un espíritu atento" "y distinto el que estan preciso y diferente de todos los otros que no comprende en sí más que lo que aparece manifiestamente". (Principios I, 45). Diríamos que lo claro es lo interno y lo distinto lo externo o mejor aún lo relacional del conocimiento evidente.

Hay aún otra clase de evidencia, de una dignidad mayor que la evidencia adecuada, es la evidencia apodíctica, aquella que se revela a una reflexión crítica, como siendo al par "la imposibilidad absoluta de que se conciba su no ser" $(6,2)$. Y que no implica la evidencia adecuada: "La adecuación y la apodicticidad de una evidencia no tienen por fuerza 
que ir mano a mano" $(9,3)$. La experiencia trascendental en general es para Husserl ejemplo de una evidencia apodíctica y no adecuada, en la que "la actualidad viva del yo" es lo único experimentado adecuadamente.

Hay pues en Husserl una evidencia de amplísima acepción, identificable con experiencia -que aún puede ser solamente presunta,- que puede hacerse perfecta en dos sentidos: uno, el de la adecuación, identificable con la evidencia cartesiana y en otro, el de la apodicticidad. La filosofía tiene como tarea buscar evidencias que, apodícticas ellas, traigan apodícticamente consigo la evidencia de preceder como primeras en sí, a todas las evidencias imaginables $(6,3)$.

Describiéndonos fenomenológicamente la evidencia dice de ella Husserl en el parágrafo que comentamos "con respecto a ciertos objetos puede ser un suceso ocasional de la vida de la conciencia, pero es también un rasgo esencial y fundamental de la vida intencional". "Representa una posibilidad, meta de una intención que tiende a realizarse". "Toda conciencia o tiene ya el carácter de evidencia o tiende por esencia a darlo auténticamente".

"En el proceso de la verificación - dice Husserl- en lugar de lo presunto mismo puede surgir algo distinto y surgir en el modo del ello mismo, con lo cual fracasa la posición de lo asunto y toma por su parte el carácter de nulo".

"La inexistencia es tan sólo una simple modalidad de la simple existencia". Aquí habla Como cualquier idealista al considerar al "no ser" como un modo del ser y no la nada.

Agrega por fin que la evidencia no sólo es correlativa a la modalidad existencia-inexistencia sino también a las del ser en general, como ser posible, probable, dudoso y aun a las que tienen su origen en la esfera del sentimiento y de la voluntad como el ser valioso y el ser bueno.

Hablando de realidad y cuasi realidad señala el filósofo que un concepto universal de posibilidad repite modificados en el modo de lo imaginable, lo "como si" o lo fantaseado -como se le llame- todos los modos del ser, empezando por la simple certeza de la existencia. Hay así modos de conciencia de la cuasi-posibilidad paralelos a los de la posicionalidad. Y realidades de la, "fantasía" paralelas a las de la realidad. Es un paralelo completo que incluye aun los peculiares modos de evidencia en los respectivos modos del ser y asimismo las peculiares potencialidades del hacer evidente. El "aclarar" en esta sombra perfecta no nos da el ser sino la posibilidad del ser. Aquí Husserl como que nos "muestra una fotografía" de las esencias que nos "presentará personal- 
mente" sólo mucho después: Las esencias son posibilidades. Nos adelanta estos conceptos preparando su "presentación".

Nos hace ver Husserl que los anteriores son problemas formales universales del análisis intencional e investigaciones sobre el origen fenomenológico de los conceptos fundamentales y principios lógicos formales y aun más que "estos conceptos en su universalidad ontológico formal son el índice de las leyes de una estructura universal de toda vida de conciencia por virtud de la cual y únicamente por virtud de la cual -como se goza este Herr en su idealismo- tienen para nosotros un sentido, y pueden tenerlo la verdad y la realidad".

"Sólo podemos estar seguros del ser real por medio de la síntesis de verificación evidente". Antes de ella sólo había "cogitata" de que tengo conocimiento en el modo posicional de creencia cierta. Sólo la evidencia hace que tenga sentido para nosotros un objeto, realmente existente, verdadero, justamente válido, con todas las determinaciones que le corresponden para nosotros bajo el título de verdadera esencia suya. Toda razón de ser brota de aquí, brota pues de nuestra subjetividad trascendental misma. "Toda imaginable adecuación surge como verificación nuestra, es nuestra síntesis, tiene en nosotros su último fundamento trascendental": De veras que el estridente clarín del idealismo solipsistoide del señor Husserl hiere los oídos con demasiada fuerza.

\section{LA EVIDENCIA HABITUAL Y LA POTENCIAL.}

Evidencia habitual: "Toda evidencia me lesa un patrimonio duradero". A la realidad contemplada auténticamente puedo tornar "siempre de nuevo" en cadenas de nuevas evidencias que serán como restauraciones de la primera evidencia; el yo "gana una nueva propiedad duradera con cada acto de un nuevo sentido objetivo irradiado por él". "Yo me resuelvo, y la'vivencia, el acto, transcurre, pero la resolución perdura". (32 - "El yo como sustrato de habitualidades").

Debemos además considerar -observa Husserl- que "la identidad del objeto presunto en cuanto tal, tampoco la identidad del vərdaderamente existente, ni luego la identidad de la adecuación entre este objeto presunto y el verdaderamente existente son un momento real en la corriente de la evidencia y la verificación. Se trata de una inmanencia ideal". Y sobre ésta ya había dicho: "Es un estar dentro de ella completamente sui generis, no como parte integrante real sino idealmente, como algo intencional, como algo que aparece" (refiriéndose al objeto en la conciencia). (18.1). 
Evidencia potencial: La inmanencia remite "a ulteriores órdenes de sintesis posibles, inherentes a la esencia de esa inmanencia". "Sin la infinitud del horizonte potencial y sus posibilidades no habría para nosotros ser estable y permanente, mundo real ni ideal. Estos brotan para nosotros de la evidencia o de la presunción de poder hacerlos evidentes y de reproducir la evidencia lograda".

"Todo ente es en si" en un sentido amplísimo y se toma frente al accidental "para mi" de los actos. aislados. Este "en si" alude a la evidencia no como hecho sino como potencialidades susceptibles de ser repetidas hasta lo infinito como hechos de la vida de la conciencia "ante todo a las de infinidad de asunciones sintéticamente referidas a uno y el mismo objeto y a su verificación. Pues la evidencia aislada no crea lodavía un ser permanente".

La habitualidad de la evidencia es, pues, su característica trascendental de poder ser siempre repetida de nuevo. La potencialidad se refiere al horizonte, en particular del modo mencionado en el párrafo anterior.

"El descubrimiento del horizonte de la experiencia es lo único que aclara la realidad del mundo y su trascendencia, y muestra luego que es inseparable de la subjetividad trascendental constituyente de todo sentido y realidad del ser". Es la tesis que el filósofo ha de afirmar aquí.

¿Qué es esto de horizonte de la experiencia? Cuando las evidencias dan su objeto auténtica pero unilateralmente, como aquellas, gracias a las cuales existe para nosotros "un mundo objetivo real" en el modo de la experiencia exterior, único posible para ellas, también nos remiten a infinitudes de evidencias. Su unilateralidad -un multiforme horizonte de anticipaciones no confirmadas pero menesterosas de confirmación o sea, contenidos meramente asumidos que remilen a las respectivas evidencias potenciales" (28. 1) - se perfecciona con cada tránsito sintético de una evidencia a otra, pero sin posibilidad de una síntesis que concluya en una evidencia adecuada; "antes bien, toda síntesis lleva consigo nuevas presunciones y coasunciones no confirmadas", al par abierta la posibilidad de que la creencia en la realidad que entra en la anticipación no se confirme. De todos modos es la experiencia exterior la única fuerza verificativa de sus objetos, de todas las realidades objetivas en la forma de la "síntesis de concordancia".

Pero la circunstancia de que esta forma y la de la evidencia que dá auténticamente su objeto sea y haya de ser "trascendente" a la conciencia, no altera el hecho de ser en la vida de la conciencia sola, en quien se constituye como inseparable de ella lo trascendente y quien, 
como conciencia del mundo en especial, lleva inseparablemente en sí el sentido de mundo y el de "este mundo realmente existente". (Nos dice el señor Husserl).

El mundo viene a ser, pues, "una idea infinita referida a infinitưdes de experiencias que deben ser concordes, una idea correlativa a la idea de una evidencia empírica perfecta, una sintesis acabada de experiencias posibles".

Aquí aparece con mucha claridad la posición husserliana. Y por lo mismo, pese a la dificultad de comprensión y a la complicación de su pensamiento, su ingenuidad, su debilidad. Emite aquí afirmaciones parecidas a las de cualquier idealismo. El modo como resuelve la trascendencia en la inmanencia nos parece -apliquemos el calificativo en esta oportunidad, pues muy pocas, o ninguna más se presentarán en que Husserl merezca precisamente éste- pueril. El problema de siempre, resuelto conforme a una posición de siempre, con sus fallas de siempre: "en la vida de la conciencia sola se constituye como inseparable de ella todo lo trascendental"; "el mundo es una idea", a estos extremos llega el querer construir una filosofía rabiosamente apodíctica y para destacar aun más la cercanía a cualquier idealismo, cl mundo es, también aquí, una "tarea infinita" como lo vamos a ver.

Continúa Husserl: "se comprenden ahora los grandes problemas de autoexhibición trascendentales del Ego".. Este concepto nos parece decisivamente importante, tanto que creemos que puede identificarse la autoexhibición con la fenomenología misma en cuanto a tarea y lo que es aun más, en cuanto a posición filosófica en general, es así que Husserl intitula el parágrafo 41, último de la cuarta meditación, y de la edición castellana que comentamos: "La autoexhibición fenomenológica del Ego cogito como idealismo trascendental". Es esta "Autoexhibición" la vía que Descartes no tomó, y sí el profesor de Friburgo; en ella está la originalidad de su idealismo, el tono, el color del mismo. "Este idealismo - dice no es un repertorio de juegos de argumentación para ganar el premio de la victoria en la lucha dialéctica con los "realismos"; es el efectivo trabajo llevado a cabo a base de todo tipo de ente imaginable para mí... con el propósito de hacer al exhibición de su sentido". Es pues un idealismo obrero y no guerrero, más bien el de una República de Trabajadores y no el de un Imperio de Guerreros. Más que atacar al enemigo -esto fué hecho parcialmente en las "investigaciones" que sólo preparan para su idealismo y no lo constituyen- prefiere "explorar" y enriquecer el propio terreno, el cogito, hacerse fuerte en él. Así, es que dice: "la prueba de este idealismo es la fenomenología misma" 
anatematizando contra toda posición que intente separar fenomenología e idealismo trascendental.

Nos da esta caracterización de "Verdadero Ser y Verdad" (en todas sus modalidades): designa una distinción estructural dentro de las variedades infinitas de cogitaciones "reales y posibles" que se refieren a "cada uno de los objetos presuntos y presumibles para mí en cuanto Ego trascendental".

"Objeto realmente existente es el sistema singular de las evidencias referentes a él, de tal suerte sintéticamente conexas, que se sucldan en una evidencia total", "acaso infinita".

"Problema de la constitución trascendental de objeto existente en un sentido estricto" es el "poner en claro la esiructura esencial de todas sus estructuras inferiores, o también poner en claro la estructura esencial de las dimensiones infinitas con que se constituye sistemáticamente su sintesis ideal infinita".

Refiriéndose particularmente a conceptos establecidos al tratar de las especificaciones del objeto según los modos de conciencia, y sobro todo de las especificaciones lógico-formales (ontológico-formales): "modos del algo en general" y ontológico-materiales, nos hace en seguida ver Husserl que tenemos:

a) Investigaciones universales formales que se atienen al concepto lógico-formal (ontológico-formal) de objeto en general, y

b) Problemas planteados para las supremas categorías de las "regiones" de objetos. Así de aquellas que figuran bajo el título de "mundo objetivo": "Es menester una teoría constitutiva de la naturaleza física", dada siempre como real, y esto implica una siempre supuesta por anticipado del hombre, de la sociedad humana, de la cultura, etc. Cada uno de estos títulos representa una gran disciplina con diversas direcciones de investigación, correspondientes a los conceptos ontológicos parciales e ingenuos".

Aclara Husserl que se trata de descubrir la intencionalidad implícita como vivencia trascendental en la experiencia cuyos horizontes brotan continuamente con un determinado estilo para hallar una "estructura intencional de las evidencias en su unidad sintética, respecto do los objetos reales". Pone como ejemplo la fundamentación en grados de los objetos no objetivos; "el tiempo inmanente, la vida que se constituye en y por sí misma". Acerca de este mismo caso que pone como ejemplo, decía: "La distinción entre la conciencia del tiempo y el tiempo mismo puede también expresarse como la distinción entre la vivencia interna al tiempo (o su forma temporal) y sus maneras de aparecer 
- variantes correspondientes. Como estas maneras de aparecer de la conciencia del tiempo son, también ellas, "vivencias intencionales" Y en la reflexión tienen a su vez necesariamente que estar dadas como temporalidades, topamos con una paradógica propiedad fundamental de la vida de la conciencia que parece, pues, estar gravada de un regreso infinito. La aclaración y comprensión de este hecho depara extraordinarias dificultades". Concedemos la razón esta vez al filósolo cuya filosofía no aceptamos: las dificultades consisten en un regreso al infinito superado tan sólo por ese infatigable optimismo "trabajador" del profesor de Friburgo.

Pueden las cinco meditaciones husserlianas llamarse, respectivamente: "Planes para el viaje", "Descubrimiento", "Conquista", "Colonización" y aun "Vida espiritual y social" del continente -ese continente cosmos- de la experiencia trascendental: "Planes", la introducción; "Descubrimiento", la primera ("camino"); "Conquista", la segunda ("exploración y conquista"); "Colonización", la tercera (traza las grandes demarcaciones); "Vida espiritual y social", la cuarta y la quinta. (El Yo y los problemas de la intersubjetividad).

La tercera meditación que comentamos es la más breve de las cinco, y al mismo tiempo de las más importantes: trata de los problemas de la verdad y la realidad. Prestamos especial importancia a la evidencia, nombre que se repetirá en casi todos los parágrafos de esta meditación. Y no por azar: la evidencia es el criterio de verdad en Husserl.

Hemos tratado de hacer el comentario ante todo con el mismo Husserl, con líneas explicativas, aclaratorias, de otras meditaciones que la tercera. Dada la dificultad de comprensión de su filosofía, proclamada por el mismo filósofo y no demasiado exagerada, si exagerada por Pfänder, nos parece la principal tarea la que ayude a contestar la pregunta: ¿Qué nos quiere decir este señor?

Aun así la crítica a quien parece sólo "asintóticamente" comprensible, es indispensable. La que podríamos llamar objetiva, la que al resultado obtenido en contraste con el fin perseguido es, por ejemplo, la que hace, entre otros Don Antonio Caso, a propósito de la quinta meditación: violación del método, que coloca a la fenomenología en el dilema de: o apodicticidad sin salir del solipsismo, o logro del "grado superior" del verdaderamente filosófico, sacrificando la apodicticidad. A nosotros nos parece que aun esta apodicticidad anterior a la quinta meditación no existe: Hay partes débiles, artificialmente soldadas, sin "unión esencial". Ejemplo: la insuficiente superación del regreso en la conciencia del tiempo ya señalada, y sobre todo en la caracterización de la evi- 
dencia apodíctica - concepto tan fundamental- $(6,2)$, en el fallido intento de superar el principio de contradicción --fundamentado en una mayor, primera apodicticidad, y no fundamentante según Husserl, cayendo al tratar sin éxito de superarlo en un tampoco superado regreso.

Nos parece además que al tratar de "barrer", de "limpiar" las "impurezas" contingentes con la "epojé" no consigue sino una palidez "aséptica", si se nos permite llamarla así, sin lograr tampoco la apodicticidad buscada. Es una filosofía que no sólo no atiende a la vida y al gusto, sino que $-\mathrm{y}$ en esto no es superación del idealismo crítico que tiene algún sentido dialéctico- no atiende tampoco, siquiera al movimiento, al devenir, a la dialéctica. Es el suyo un mundo de cadáveres.

Considerando nosotros, con Hegel, que la Historia de la Filosofía es el gigantesco diálogo del espíritu humano consigo mismo, la filosofía husserliana no es ni la última palabra, ni la más acertada dicha en él, sin negarle esa originalidad y fecundidad que parecen justificar y explicar el hecho de haber sido la fenomenología del pensador de Moravia el movimiento filosófico que ha cobrado más beligerancia en lo que va del siglo. Pero no seamos demasiado corteses con el filósofo: nos ofrece una nueva cárcel idealista, con los inconvenientes de siempre y algunos más.

Y por último, opinamos que la lenomenología husserliana es, también ella, una "evidencia presuntiva" siguiendo el horizonte de la cual, no hallamos ninguna "evidencia verificativa" de esa "presuntiva" asunción inicial. Esta verificación que tampoce parece - como la asunción de la experiencia exterior- ser capáz de concluir, en alguna "evidencia adecuada" ha tomado antes bien caminos - Scheler y Heidegger- que arrancó de esa concepción del tiempo, el irracionalizador tan deficiente en el racionalista de Moravia- que nos muestran nuevos y otros paisajes, con sus "horizontes" también, siempre abiertos al esfuerzo del espíritu del hombre. 